\title{
A new perspective on the spatio-temporal variability of soil moisture: temporal dynamics versus time-invariant contributions
}

\author{
H. Mittelbach and S. I. Seneviratne \\ Institute for Atmospheric and Climate Science, ETH Zurich, Universitätstrasse 16, 8092 Zurich, Switzerland \\ Correspondence to: H. Mittelbach (heidi.mittelbach@env.ethz.ch), S. I. Seneviratne (sonia.seneviratne@env.eth.ch)
}

Received: 22 December 2011 - Published in Hydrol. Earth Syst. Sci. Discuss.: 16 January 2012

Revised: 12 May 2012 - Accepted: 16 June 2012 - Published: 20 July 2012

\begin{abstract}
Knowledge about the spatio-temporal variability of soil moisture is essential to understand and predict processes in climate science and hydrology. A significant body of literature exists on the characterization of the spatial variability and the rank stability (also called temporal stability) of absolute soil moisture. Yet previous studies were generally based on short-term measurement campaigns and did not distinguish the respective contributions of time-varying and time-invariant components to these quantities. In this study, we investigate this issue using measurements from 14 grassland sites of the SwissSMEX soil moisture network (spatial extent of approx. $150 \times 210 \mathrm{~km}$ ) over the time period May 2010 to July 2011 . We thereby decompose the spatial variance of absolute soil moisture over time in contributions from the spatial variance of the mean soil moisture at all sites (which is time-invariant), and components that vary over time and are related to soil moisture dynamics. These include the spatial variance of the temporal soil moisture anomalies at all sites and the covariance between the site anomalies to the spatial mean at a given time step and those for the temporal mean values. The analysis demonstrates that the timeinvariant term contributes $50-160 \%$ (on average $94 \%$ ) of the spatial soil moisture variance at any point in time, while the covariance term generally contributes negatively to the spatial variance. On the other hand, the spatial variance of the temporal anomalies, which is overall most relevant for climate and hydrological applications because it is related to soil moisture dynamics, is relatively limited and constitutes at most $2-30 \%$ (on average $9 \%$ ) of the total variance. Nonetheless, this term is not negligible compared to the temporal anomalies of the spatial mean. These results suggest that a large fraction of the spatial variability of soil moisture
\end{abstract}

assessed from short-term campaign may be time-invariant if other regions present a similar behavior. Moreover, we find that the rank (or temporal) stability concept, when applied to absolute soil moisture at the sites, mostly characterizes the time-invariant patterns. Indeed, sites that best represent the mean soil moisture dynamics of the network are not the same as those that best reflect mean soil moisture at any point in time. Overall, this study shows that conclusions derived from the analysis of the spatio-temporal variability of absolute soil moisture need not generally apply to temporal soil moisture anomalies, and hence to soil moisture dynamics.

\section{Introduction}

Soil moisture is an essential variable in climate and hydrological science through its impact on the energy and water balance (see Seneviratne et al., 2010, for a review). Knowledge about soil moisture and its spatio-temporal variability, which is impacted by the heterogeneity of different characteristics, such as soil texture, vegetation, topography and meteorological conditions, is essential to improve climate and hydrological modeling, to derive remote sensing-based soil moisture estimates, and to optimize soil moisture monitoring networks (e.g. Vinnikov et al., 1996; Western et al., 2002; Jacobs, 2004; Koster et al., 2004; Seneviratne et al., 2006; Robinson et al., 2008; Brocca et al., 2010).

Frequently used frameworks to investigate spatiotemporal variability of soil moisture patterns include geostatistical methods (Famiglietti et al., 2008; Western et al., 2004; Entin et al., 2000), the relationship between the spatial variance and the spatial mean soil 
moisture (e.g. Famiglietti et al., 1999; Brocca et al., 2010), and rank stability analyses (e.g. Vachaud et al., 1985; Martínez-Fernández and Ceballos, 2003; Tallon and Si, 2004; Zhou et al., 2007). These approaches are used to analyze and compare the spatial variability of soil moisture at multiple depths, across spatial scales and under different moisture conditions and are based on ground observations and stochastic analysis of the unsaturated water flow (e.g. Famiglietti et al., 1999; Teuling et al., 2006; Vereecken et al., 2007). Investigations of the potential controls on soil moisture variability are for instance provided in Western et al. (1999), Albertson and Montaldo (2003), Cosh (2004), and Teuling and Troch (2005), and generally focus on parameters or variables such as soil texture, vegetation cover, topography, as well as land surface fluxes. The role of meteorological and climate forcing for spatial soil moisture variability has only been considered in few studies (Vinnikov et al., 1996; Robock et al., 1998; Entin et al., 2000). For its part, the concept of temporal stability proposed by Vachaud et al. (1985) aims at identifying the most representative soil moisture site within a given network and has been suggested to be relevant for improving monitoring strategies or for the upscaling of soil moisture (e.g. Kamgar et al., 1993; Guber et al., 2008; Brocca et al., 2009).

Most of the mentioned studies are based on data sets that were collected during short-term field campaigns. These studies often include observations for wet and dry conditions but no continuous long-term time series. However, already Bell et al. (1980) emphasized the need for long-term measurements to study the spatial variability over a large range of spatial mean moisture contents.

Long-term time series are furthermore essential to investigate soil moisture dynamics, i.e. variations of soil moisture in time. Previous analyses (Seneviratne, 2003; Seneviratne et al., 2004) indicated that temporal soil moisture variations may be more stable in space than absolute soil moisture. Reasons can be found in the different spatial scale of soil moisture variations characterized either by local (e.g. soil texture, land cover, topography) or regional scale pattern (e.g. weather and climate anomalies) (Vinnikov et al., 1996; Robock et al., 1998). However, to our knowledge no extensive analyses have been provided on this topic so far.

In the present study, we use continuous 15-month long soil moisture measurements from 14 sites of the SwissSMEX soil moisture network (Sect. 3.1), which cover a spatial extent of $150 \times 210 \mathrm{~km}$. The time series are decomposed in their temporal mean and anomalies. We apply the concepts of spatial variability and temporal stability to the decomposed time series, to assess the extent to which they respectively contribute to the overall spatial soil moisture variability. In addition, we also investigate whether commonly applied concepts such as that of temporal stability are relevant from the point of view of soil moisture dynamics.

\section{Methods}

\subsection{Framework to distinguish between time-varying and time-invariant contributors to spatial variability}

Spatio-temporal variability of soil moisture is characterized by the spatial and temporal statistics of soil moisture. The spatial variability of soil moisture has been investigated in a number of previous studies using the relation between the spatial variance and the spatial mean of absolute soil moisture (e.g. Famiglietti et al., 1999, 2008; Brocca et al., 2007). Here we propose a new approach, whereby we consider the respective contributions of time-varying and time-invariant factors to the overall spatial variability of soil moisture at any point in time.

For more clarity, we will denote hereafter the mean $\mu$, variance $\sigma^{2}$, and standard deviation $\sigma$ with the subscript $\widehat{n}$ for the spatial statistics, and with the subscript $\widehat{t}$ for the temporal statistics. Let $S_{t n}$ be the soil moisture of site $n \subset[1, \ldots N]$ at time $t \subset[1, \ldots T]$ ( $S_{t n}$ being defined as scalar). Its spatial mean $\mu_{\widehat{\mathrm{n}}}\left(S_{t n}\right)$ and spatial variance $\sigma_{\widehat{\mathrm{n}}}^{2}\left(S_{t n}\right)$ at any time step $t$ are defined as:

$$
\begin{aligned}
& \mu_{\widehat{\mathrm{n}}}\left(S_{t n}\right)=\frac{1}{N} \sum_{n=1}^{N}\left(S_{t n}\right), \\
& \sigma_{\widehat{\mathrm{n}}}^{2}\left(S_{t n}\right)=\frac{1}{N} \sum_{n=1}^{N}\left(S_{t n}-\mu_{\widehat{\mathrm{n}}}\left(S_{t n}\right)\right)^{2} .
\end{aligned}
$$

Similarly, the temporal mean of soil moisture at any site $n$ is defined as:

$\mu_{\mathfrak{\mathfrak { t }}}\left(S_{t n}\right)=\frac{1}{T} \sum_{t=1}^{T}\left(S_{t n}\right)$.

Note that of ease for notation we will use the symbol $M_{t n}$ to refer to the temporal mean $\mu_{\hat{\mathrm{t}}}\left(S_{t n}\right)$.

Here we extend the classical framework that generally compares $\mu_{\widehat{\mathrm{n}}}\left(S_{t n}\right)$ and $\sigma_{\widehat{\mathrm{n}}}^{2}\left(S_{t n}\right)$ by decomposing $S_{t n}$ into its temporal mean $M_{t n}$ and its temporal anomalies $A_{t n}$. This allows us to distinguish between spatio-temporal aspects that are time-invariant and those related to soil moisture dynamics. Formally, this is expressed as follows:

$S_{t n}=M_{t n}+A_{t n}$.

The corresponding equation for the mean of all sites is

$\mu_{\widehat{\mathrm{n}}}\left(S_{t n}\right)=\mu_{\widehat{\mathrm{n}}}\left(M_{t n}\right)+\mu_{\widehat{\mathrm{n}}}\left(A_{t n}\right)=M_{t \widehat{\mathrm{n}}}+A_{t \widehat{\mathrm{n}}}$.

Using Eqs. (4) and (5), it is possible to decompose $\sigma_{\widehat{n}}^{2}\left(S_{t n}\right)$ in time-varying and time-invariant components by resolving Eqs. (4) and (5) into Eqs. (1) and (2):

$\sigma_{\widehat{\mathrm{n}}}^{2}\left(S_{t n}\right)=\frac{1}{N} \sum_{n=1}^{N}\left[\left(M_{t n}+A_{t n}\right)-\left(M_{t \widehat{\mathrm{n}}}+A_{t \widehat{\mathrm{n}}}\right)\right]^{2}$. 
Eq. (6) can then be reexpressed as follows:

$$
\begin{aligned}
\sigma_{\widehat{\mathrm{n}}}^{2}\left(S_{t n}\right)= & \frac{1}{N} \sum_{n=1}^{N}\left[\left(M_{t n}-M_{t \widehat{\mathrm{n}}}\right)^{2}\right. \\
& +2\left(M_{t n}-M_{t \widehat{\mathrm{n}}}\right)\left(A_{t n}-A_{t \widehat{\mathrm{n}}}\right) \\
& \left.+\left(A_{t n}-A_{t \widehat{\mathrm{n}}}\right)^{2}\right],
\end{aligned}
$$

resulting in the following equation:

$\sigma_{\widehat{\mathrm{n}}}^{2}\left(S_{t n}\right)=\sigma_{\widehat{\mathrm{n}}}^{2}\left(M_{t n}\right)+2 \operatorname{cov}\left(M_{t n}, A_{t n}\right)+\sigma_{\widehat{\mathrm{n}}}^{2}\left(A_{t n}\right)$,

where $\sigma_{\widehat{\mathrm{n}}}^{2}\left(M_{t n}\right)$ is the spatial variance of temporal mean soil moisture, $\sigma_{\widehat{\mathrm{n}}}^{2}\left(A_{t n}\right)$ is the spatial variance of anomalies, and $\operatorname{cov}\left(M_{t n}, A_{t n}\right)$ is the spatial covariance between the temporal mean soil moisture of a site and its respective anomaly.

Note that Eq. (8) can also be expressed as follows:

$$
\begin{aligned}
\sigma_{\widehat{\mathrm{n}}}^{2}\left(S_{t n}\right) & =\sigma_{\widehat{\mathrm{n}}}^{2}\left(M_{t n}\right) \\
& +2 \rho\left(M_{t n}, A_{t n}\right) \sigma\left(M_{t n}\right) \sigma\left(A_{t n}\right)+\sigma_{\mathrm{n}}^{2}\left(A_{t n}\right),
\end{aligned}
$$

where $\rho\left(M_{t n}, A_{t n}\right)$ refers to the correlation between $M_{t n}$ and $A_{t n}$.

Equation (8) allows us to analyze the spatio-temporal variability of soil moisture considering its temporal mean $M_{t n}$ state and its dynamics $A_{t n}$. Furthermore, the temporal evolution of the spatial variance and the contribution of its single components can be investigated. Note that $\sigma_{\widehat{\mathrm{n}}}^{2}\left(M_{t n}\right)$ is timeinvariant, while $\sigma_{\widehat{\mathrm{n}}}^{2}\left(A_{t n}\right)$ and $\operatorname{cov}\left(M_{t n}, A_{t n}\right)$ vary over time.

\subsection{Relating the rank stability concept to time-varying and time-invariant soil moisture components}

The concept of temporal stability proposed by Vachaud et al. (1985) is used in several previous studies to identify sites where soil moisture is considered to be most representative of the spatial mean soil moisture within a network (e.g. Kamgar et al., 1993; Teuling et al., 2006; Brocca et al., 2010). Following Vachaud et al. (1985), the difference $\Delta S_{t n}$ between the soil moisture $S_{t n}$ and the spatial mean soil moisture $\mu_{\widehat{\mathrm{n}}}\left(S_{t n}\right)$ is defined as:

$\Delta S_{t n}=S_{t n}-\mu_{\widehat{n}}\left(S_{t n}\right)$.

Its relative difference is

$\delta S_{t n}=\frac{\Delta S_{t n}}{\mu_{\widehat{\mathrm{n}}}\left(S_{t n}\right)}$,

and its temporal mean $\mu_{\hat{\mathfrak{t}}}\left(\delta S_{t n}\right)$ and temporal standard deviation $\sigma_{\mathfrak{t}}\left(\delta S_{t n}\right)$ are estimated as:

$\mu_{\mathfrak{\mathrm { t }}}\left(\delta S_{t n}\right)=\frac{1}{T} \sum_{t=1}^{T}\left(\delta S_{t n}\right)$,

$\sigma_{\mathfrak{\mathrm { t }}}\left(\delta S_{t n}\right)=\sqrt{\frac{1}{T} \sum_{t=1}^{T}\left(\delta S_{t n}-\mu_{\mathfrak{\mathrm { t }}}\left(\delta S_{t n}\right)\right)^{2}}$.
The $\mu_{\mathfrak{t}}\left(\delta S_{t n}\right)$ and $\mu_{\mathfrak{t}}\left(\Delta S_{t n}\right)$ of the sites are ranked from the smallest to the largest difference. Sites closest to $\mu_{\widehat{n}}\left(S_{t n}\right)$ (i.e. $\left.\mu_{\hat{\mathrm{t}}}\left(\delta S_{t n}\right) \approx 0\right)$ are considered to be the most representative of the overall network.

Using Eq. (4), the temporal stability analyses (Eqs. 1013) can be extended by including the different contributors to absolute soil moisture. As $A_{t n}$ can have negative values, the absolute values of the difference for $A_{t n}$ and $M_{t n}$ are used:

$\left|\Delta A_{t n}\right|=\left|A_{t n}-\mu_{\widehat{\mathrm{n}}}\left(A_{t n}\right)\right|$,

$\left|\Delta M_{t n}\right|=\left|M_{t n}-\mu_{\widehat{\mathrm{n}}}\left(M_{t n}\right)\right|$.

The temporal mean and standard deviation of the anomalies $\mu_{\widehat{t}}\left(\Delta A_{t n}\right)$ and $\sigma_{\mathfrak{t}}\left(\Delta A_{t n}\right)$ can be analyzed to provide a ranking of the sites according to their respective deviation from the overall mean. Similarly, the absolute deviation of the temporal mean $\Delta M_{t n}$ can also provide a ranking. To relate the new ranking to the ranking of the overall soil moisture, the framework by Vachaud et al. (1985) is adapted here by considering the absolute terms $\left|\delta S_{t n}\right|$ and $\left|\Delta S_{t n}\right|$, respectively.

In this study, we are interested in the ranking of the single sites and not in the differences themselves. The comparison of the rank of the absolute soil moisture $S_{t n}$ with the ranks of its decomposed parts $M_{t n}$ and $A_{t n}$ allows us to make a statement on how the framework of rank stability (Vachaud et al., 1985) incorporates the soil moisture dynamics.

\section{Application to the SwissSMEX network}

\subsection{Studied network and data}

The Swiss Soil Moisture Experiment (SwissSMEX) network (http://www.iac.ethz.ch/url/research/SwissSMEX) has a spatial extent of about $150 \times 210 \mathrm{~km}$ and consists of overall 19 sites, covering different land use and climatic regimes of Switzerland. For further information about the setup and instrumentation of the network, see Mittelbach et al. (2011). In the present study, 14 grassland sites with no slope and an elevation ranging from about $200 \mathrm{~m}$ a.s.l. to about $1000 \mathrm{~m}$ a.s.l. are included. Their location, respective climatic region (Müller, 1980), and average soil texture over $50 \mathrm{~cm}$ are shown in Fig. 1. At each site, measurements of volumetric water content (VWC) at $5,10,30$, and $50 \mathrm{~cm}$ depth as well as precipitation $(P)$ and 2-m air temperature $\left(T_{\text {air }}\right)$ are available. The VWCs at the different depths were integrated over $50 \mathrm{~cm}$ using the trapezoidal method (e.g. Hupet et al., 2004) including an additional value of VWC at the surface, which is set equal to the measurement in $5 \mathrm{~cm}$ depth. The analysis is based on daily averaged data for the time period 1 May 2010 to 31 July 2011, including the particularly dry months April and May 2011.

\subsection{Relation between spatial variance and spatial mean}

Brocca et al. (2007) investigate the relation between $\sigma_{\widehat{\mathrm{n}}}^{2}\left(S_{t n}\right)$ and $\mu_{\widehat{n}}\left(S_{t n}\right)$, as well as the relation between the coefficient 


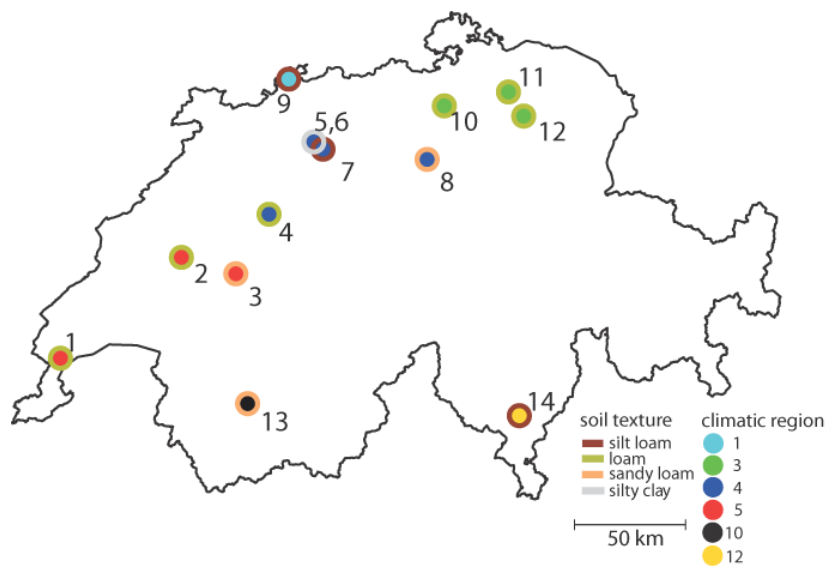

Fig. 1. Map of Switzerland showing the location, climatic region, and soil texture (according to USDA taxonomy and averaged over $50 \mathrm{~cm}$ depth) of the 14 investigated grassland sites of the SwissSMEX network. The indicated climate regions are based on the classification of Müller (1980).

of variation $\left(C V=\sigma_{\widehat{\mathrm{n}}}\left(S_{t n}\right) / \mu_{\widehat{\mathrm{n}}}\left(S_{t n}\right)\right)$ and $\mu_{\widehat{\mathrm{n}}}\left(S_{t n}\right)$, based on measurements from several networks. Based on these data, they identified an increasing spatial variability with decreasing mean soil moisture for humid climates. The corresponding relation for the measurements used in the current study with their temporal occurrence is shown in Fig. 2a and b. Similarly to Brocca et al. (2007), an increasing variability with decreasing spatial mean is found. However, the values of spatial variability scatter more widely when the spatial mean soil moisture decreases (Fig. 2a). The nearly steady spatial variability with decreasing spatial mean soil moisture for April and May 2011 is particularly seen for $\sigma_{\widehat{\mathrm{n}}}^{2}\left(S_{\mathrm{t}}\right)$. The relation for the anomalies (Fig. 2c) shows the behavior of soil moisture when the temporal mean state of each site is removed and only its dynamics are considered. A parabolic shape with smallest variability for moisture conditions close to the spatial mean $M_{t \widehat{n}}$, with $\mu_{\widehat{\mathrm{n}}}\left(A_{t n}\right) \approx 0$, is found. Interestingly, the dry period of April and May 2011 is not as outstanding for the soil moisture anomalies (Fig. 2c) as when considering the absolute soil moisture (Fig. 2a, b), given that it shows an increase in variability similar to that seen in July and August 2010.

For both absolute soil moisture as well as its anomalies, a temporal dependency in the sequence of the relation is found. Indeed, for the absolute soil moisture, highest spatial mean related to lowest spatial variance (e.g. for the DJF season) and lowest spatial mean related to highest spatial variance (e.g. for May to August) are found. On the other hand, the relations of the anomalies reflect the longer dry period from July 2010 to the beginning of August 2010 and the particularly dry April and May 2011 (see Fig. 3a for the spatial mean $P$ and $T_{\text {air }}$ during these periods).

\subsection{Time series of absolute soil moisture and its time-invariant and time-varying components}

Figure 3a displays the time series of the spatial mean and spatial standard deviation for $P$ and $T_{\text {air }}$, which show a higher and more fluctuating variability in $P$ and a more spatially homogeneous $T_{\text {air. }}$. The time series of each site as well as the spatial mean $\mu_{\widehat{\mathrm{n}}}$ of the absolute soil moisture $S_{t n}$ and its decomposed time-invariant $M_{t n}$ and time-variant $A_{t n}$ components (Eq. 8) are displayed in Fig. 3b-d. This analysis reveals that, by removing the time-invariant component, the time series are more similar and the main difference in absolute soil moisture values is induced by the time-invariant component.

Figure 4a shows the spatial mean $\mu_{\widehat{n}}\left(S_{t n}\right)$ and spatial standard deviation $\sigma_{\widehat{\mathrm{n}}}\left(S_{t n}\right)$ of absolute soil moisture. The term $\mu_{\widehat{n}}\left(S_{t n}\right)$ is positively related to $P$ and negatively related to $T_{\text {air }}$ and shows smallest variability during the winter months. While the time series of spatial mean of the anomalies $\mu_{\widehat{\mathrm{n}}}\left(A_{t n}\right)$ (Fig. 4b) show a similar behavior to $\mu_{\widehat{\mathrm{n}}}\left(S_{t n}\right)$, its standard deviation $\sigma_{\widehat{n}}\left(A_{t n}\right)$ (Fig. $4 \mathrm{~b}$, shaded area) displays a higher variability than $\sigma_{\widehat{\mathrm{n}}}\left(S_{t n}\right)$. A notable increase in $\sigma_{\widehat{\mathrm{n}}}\left(A_{t n}\right)$ is visible during longer lasting periods with no rain over the whole network, such as in July to August 2010 and April to May 2011, but also during longer lasting periods with rain at all sites, such as the end of August 2010.

The temporal evolution of the spatial variance of absolute soil moisture and its components according to Eq. (7) are shown in Fig. 4c. Their respective percentage is shown in Fig. 4d and summarized over the DJF, MAM, JJA, and SON seasons in Fig. 5. The sum bar in Fig. 5 confirms that the spatial variance of the absolute soil moisture is equal to the sum of the single terms in Eq. (8). As indicated in Fig. $4 \mathrm{~b}, \sigma_{\widehat{\mathrm{n}}}^{2}\left(S_{t n}\right)$ displays clear lower variability for the winter and spring months compared with the summer and autumn seasons. The time-invariant $\sigma_{\widehat{n}}^{2}\left(M_{t n}\right)$ contributes most to $\sigma_{\widehat{\mathrm{n}}}^{2}\left(S_{t n}\right)$ with percentages ranging from about 50 to $160 \%$, with largest percentages and exceedance of $\sigma_{\widehat{n}}^{2}\left(S_{t n}\right)$ during the DJF and MAM seasons, but also during particularly wet or dry conditions, such as in May 2010 as well as in April and May 2011. This exceedance is compensated by the timevariant contributors $\sigma_{\widehat{\mathrm{n}}}^{2}\left(A_{t n}\right)$ and $\operatorname{cov}\left(M_{t n}, A_{t n}\right)$, and reflects a negative contribution of $\operatorname{cov}\left(M_{t n}, A_{t n}\right)$ of about $50 \%$ during these periods. The contribution of $\sigma_{\widehat{\mathrm{n}}}^{2}\left(A_{t n}\right)$ is smallest and ranges between about 2 to $30 \%$ (Fig. 4). It is highest for MAM and JJA with an average percentage of $10 \%$ (Fig. 5). Interestingly, $\sigma_{\widehat{\mathrm{n}}}^{2}\left(A_{t n}\right)$ shows an increase during particularly dry periods, such as in July 2010 as well as in April and in mid-May 2011, which are not seen in $\sigma_{\widehat{n}}^{2}\left(S_{t n}\right)$. Summarized by seasons (Fig. 5), the smallest percentages of $\sigma_{\widehat{\mathrm{n}}}^{2}\left(M_{t n}\right)$ and highest percentages of the summed $\sigma_{\widehat{\mathrm{n}}}^{2}\left(A_{t n}\right)$ and $\operatorname{cov}\left(M_{t n}, A_{t n}\right)$ are found for the summer season (JJA). This indicates that the soil moisture dynamics has the largest impact on the spatial variability in this season. 
a)

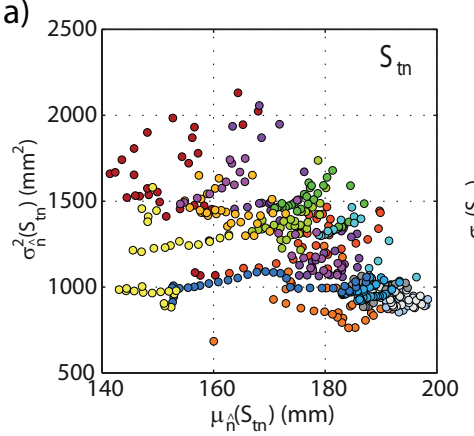

b)

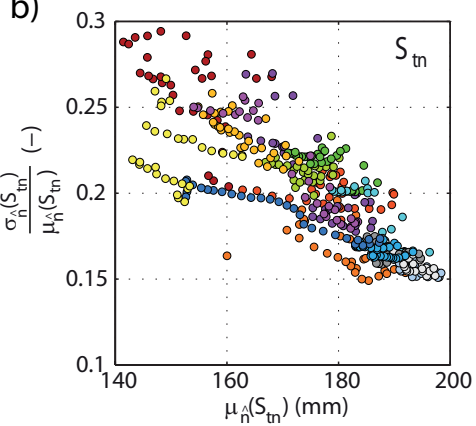

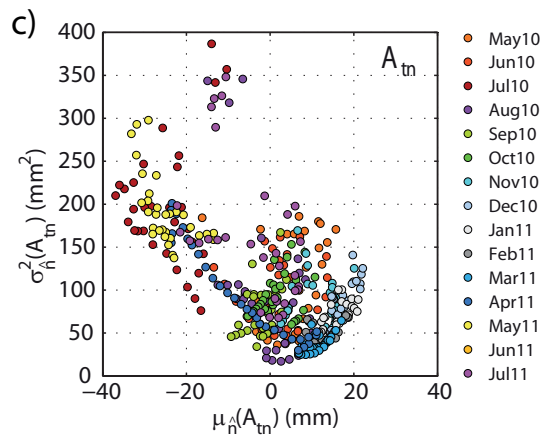

Fig. 2. Scatter plots of (a) the spatial mean $\left(\mu_{\widehat{n}}\left(S_{t n}\right)\right)$ vs spatial variance $\left(\sigma_{\widehat{n}}^{2}\left(S_{t n}\right)\right)$ of daily absolute soil moisture, (b) the coefficient of variation $\left(\sigma_{\widehat{\mathrm{n}}}\left(S_{t n}\right) / \mu_{\widehat{\mathrm{n}}}\left(S_{t n}\right)\right)$ vs. the spatial mean $\left(\mu_{\widehat{\mathrm{n}}}\left(S_{t n}\right)\right)$ of daily absolute soil moisture, as well as $(\mathbf{c})$ the spatial mean $\left(\mu_{\widehat{\mathrm{n}}}\left(A_{t n}\right)\right)$ vs. spatial variance $\left(\sigma_{\hat{\mathrm{n}}}^{2}\left(A_{t n}\right)\right)$ of daily anomalies. The different colors indicate daily data of the single months.

a)

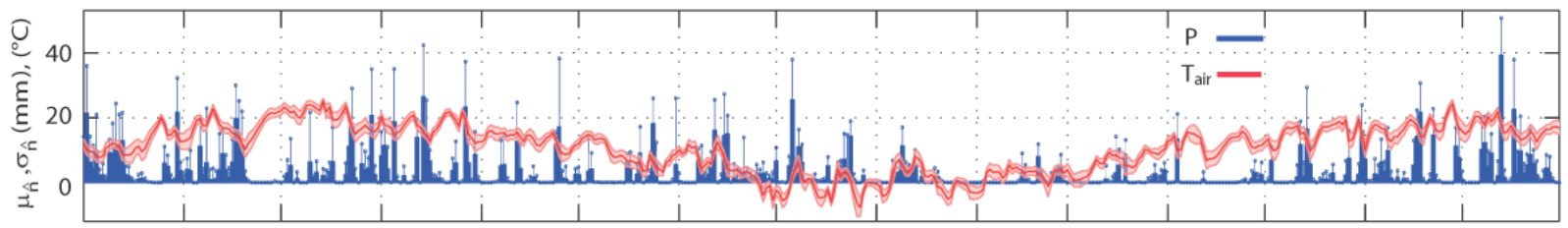

b)

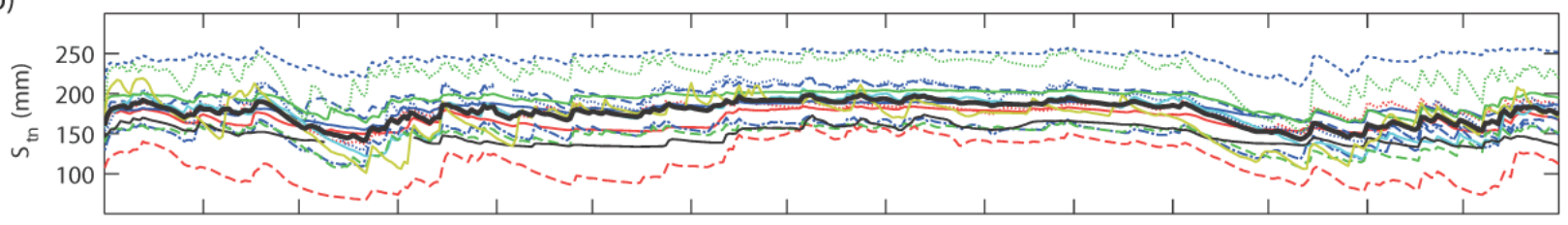

c)

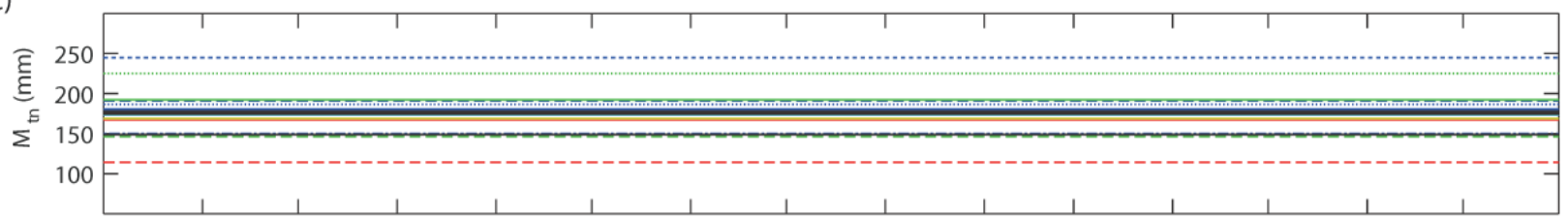

d)

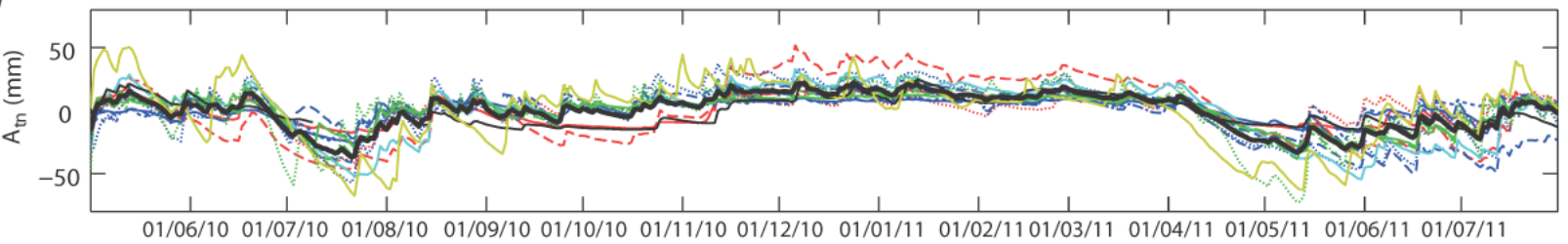

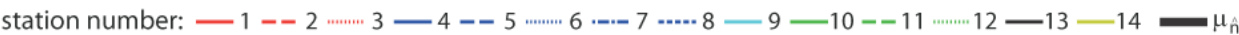

Fig. 3. Time series of spatial mean and spatial standard deviation (stem and shaded areas) for (a) precipitation $P$ and 2-m air temperature $T_{\text {air }}$. Time series of each site as well as the spatial mean (black bold lines) of (b) absolute soil moisture $S_{t n}$ and its decomposed (c) time-invariant (temporal mean) $M_{t n}$ and (d) time-varying (anomalies) $A_{t n}$ component.

The relation between the single contributors can be seen in the scatter plots of Fig. 6 . The scatter plot between $\sigma_{\widehat{n}}^{2}\left(A_{t n}\right)$ and $\sigma_{\widehat{\mathrm{n}}}^{2}\left(S_{t n}\right)$ (Fig. 6a) shows a general positive relation between these two terms. However, for $\sigma_{\widehat{\mathrm{n}}}^{2}\left(S_{t n}\right)<\sigma_{\widehat{\mathrm{n}}}^{2}\left(M_{t n}\right)$ the data scatter more widely, and moreover, the particularly dry May enhances this scatter, indicating the abovementioned dynamics, which is not found in the total soil moisture variance. A positive, mostly linear, relation between $\operatorname{cov}\left(M_{t n}, A_{t n}\right)$ and $\sigma_{\widehat{\mathrm{n}}}^{2}\left(S_{t n}\right)$ is identified in Fig. $6 \mathrm{~b}$. The contribution of $\operatorname{cov}\left(M_{t n}, A_{t n}\right)$ results in positive but also negative values, where negative values occur for $\sigma_{\widehat{n}}^{2}\left(S_{t n}\right)<$ $\sigma_{\widehat{\mathrm{n}}}^{2}\left(M_{t n}\right)$. The different sign of $\operatorname{cov}\left(M_{t n}, A_{t n}\right)$ for $\sigma_{\widehat{\mathrm{n}}}^{2}\left(S_{t n}\right)$ above or below $\sigma_{\widehat{\mathrm{n}}}^{2}\left(M_{t n}\right)$ implies a change in the relation between $\sigma_{\widehat{\mathrm{n}}}^{2}\left(M_{t n}\right)$ and $\sigma_{\widehat{\mathrm{n}}}^{2}\left(A_{t n}\right)$, which depends on the structure 

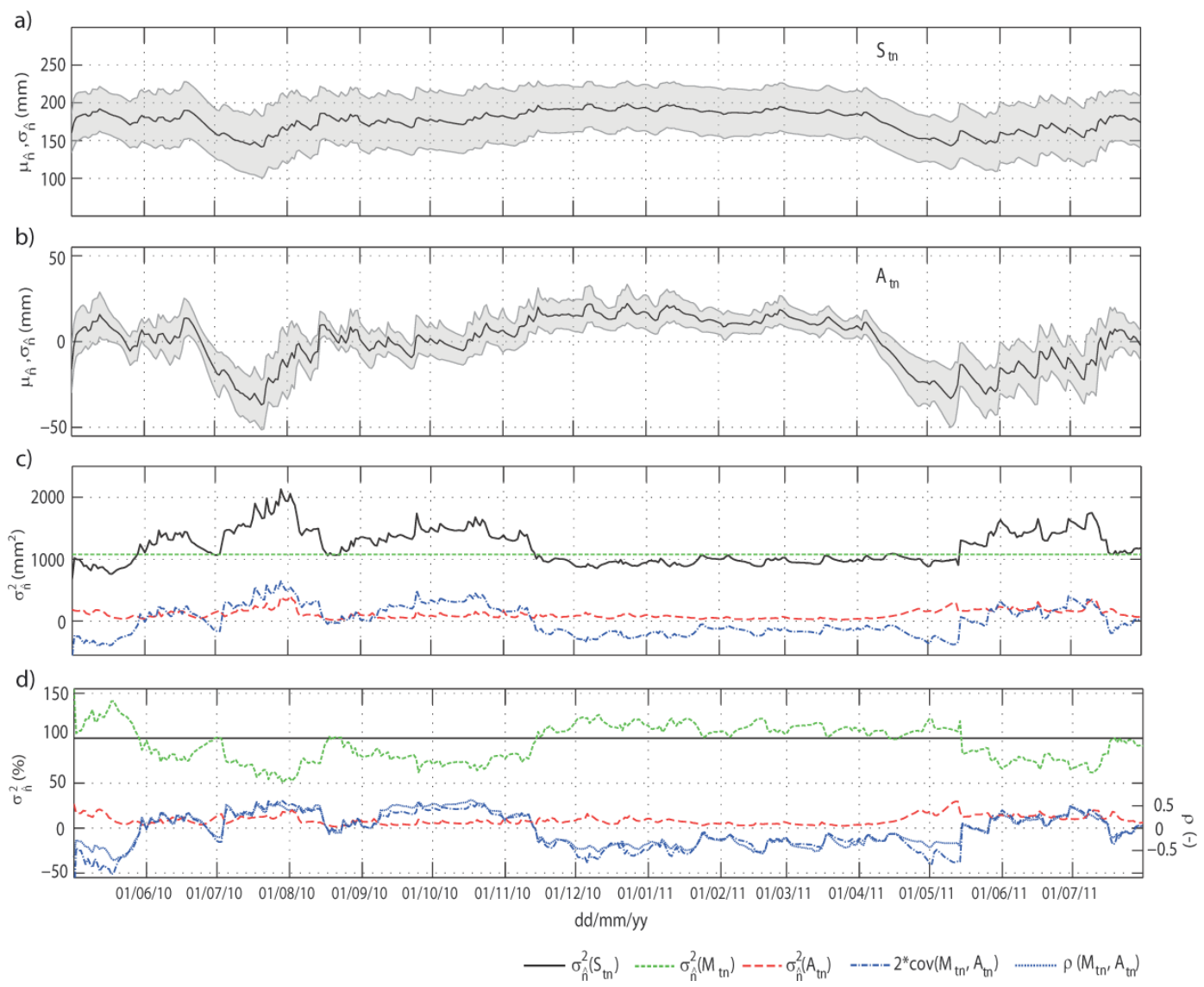

Fig. 4. Time series of spatial mean and spatial standard deviation (shaded areas) for (a) absolute soil moisture $S_{t n}$, and (b) anomalies $A_{t n}$ of absolute soil moisture. Decomposition of spatial variance of absolute soil moisture into its contributors according to Eq. (8) expressed (c) in $\mathrm{mm}^{2}$ and (d) as percentage.

of anomalies, as the variability in the mean stays the same over time.

\subsection{Temporal stability of absolute soil moisture and its dynamics}

The rank-ordered temporal mean of the absolute differences $\delta S_{t n}$ as well as of the relative differences $\Delta S_{t n}$ after Vachaud et al. (1985) with one standard deviation is shown in Fig. 7a and $b$. The temporal mean of $\delta S_{t n}$ varies between $-35 \%$ and $39 \%$; its standard deviation varies between $3 \%$ and $10 \%$ (Fig. 7b). Although the present data set is characterized by a small number of sites over a larger spatial scale, these values are comparable to values found in the literature using observations from networks with a smaller spatial extent (see e.g. Brocca et al., 2009, for a summary of the characteristics of temporal stability of different studies).

The rank-ordered absolute values of differences for the total and decomposed soil moisture $\left(\left|\mu_{\mathfrak{t}}\left(\Delta S_{t n}\right)\right|,\left|\mu_{\mathfrak{t}}\left(\delta S_{t n}\right)\right|\right.$, $\mu_{\widehat{\mathfrak{t}}}\left(\left|\Delta M_{t n}\right|\right)$, and $\left.\mu_{\mathfrak{\mathrm { t }}}\left(\left|\Delta A_{t n}\right|\right)\right)$, with one standard deviation, are shown in Figs. 7c, $d$ and 8, respectively. As expected, the ranks of $\left|\mu_{\mathfrak{t}}\left(\delta S_{t n}\right)\right|$ and $\left|\mu_{\mathfrak{t}}\left(\Delta S_{t n}\right)\right|$ have the same order.
In this study, we focus on the ordered ranks of $\left|\mu_{\mathfrak{t}}\left(\Delta S_{t n}\right)\right|$ and we analyze their relation to the time-varying and timeinvariant contributions by comparing the ranks of $\left|\mu_{\mathfrak{t}}\left(\Delta S_{t n}\right)\right|$ (Fig. 7c) with the ranks of the absolute differences of the decomposed soil moisture $\mu_{\mathfrak{t}}\left(\left|\Delta M_{\mathrm{n}}\right|\right)$ and $\mu_{\hat{\mathfrak{t}}}\left(\left|\Delta A_{t n}\right|\right)$ (Fig. 8a, b). Considering the ranks of the decomposed $S_{t n}$ (Fig. 8), it is seen that the ranks of $\left|\mu_{\mathfrak{t}}\left(\Delta S_{t n}\right)\right|$ (Fig. 7c) are mostly reflected by the ranks of $\mu_{\mathfrak{\mathrm { t }}}\left(\left|\Delta M_{\mathrm{n}}\right|\right)$ (Fig. 8a). The ranks of the temporal mean of the anomalies $\mu_{\mathfrak{t}}\left(\left|\Delta A_{\mathrm{n}}\right|\right)$ (Fig. 8b) show a contrasting sequence for the sites. The scatter plots of Fig. 9 indicate that the rank stability of $S_{t n}$ contains information about the temporal mean of soil moisture, but is not related to the dynamics of soil moisture. Hence, this suggests that, within the SwissSMEX network, the evaluation of the stability of the rank ordering of $\mu_{\mathfrak{t}}\left(\delta S_{t n}\right)$ proposed by Vachaud et al. (1985) is a measure of the rank stability of long-term mean soil moisture conditions but does not provide information on the varying spatio-temporal characteristics of the network. 


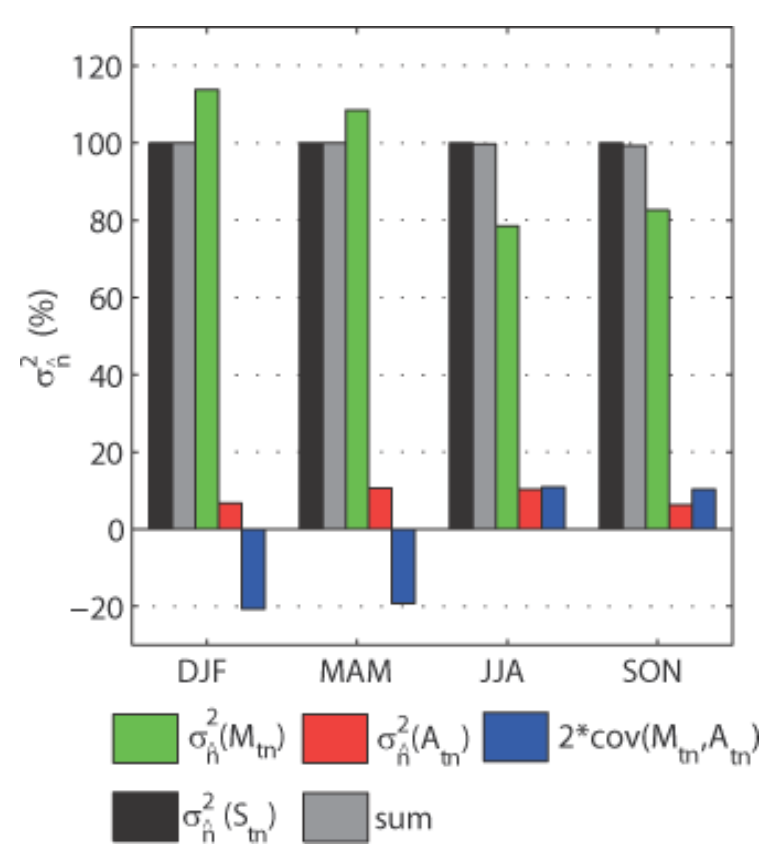

Fig. 5. Percentage of the single contributors $\left(\sigma_{\widehat{\mathrm{n}}}^{2}\left(M_{t n}\right), \sigma_{\widehat{\mathrm{n}}}^{2}\left(A_{t n}\right)\right.$ and $\left.2 * \operatorname{cov}\left(M_{t n}, A_{t n}\right)\right)$ to the spatial variance of absolute soil moisture $\sigma_{\widehat{\mathrm{n}}}^{2}\left(S_{t n}\right)$ averaged over the seasons DJF, MAM, JJA, and SON as well as their sums.

\section{Discussion}

In this study, we expand frequently used hydrological frameworks for the analysis of the spatio-temporal variability of soil moisture within a given network to distinguish between the contribution of the temporal mean and anomalies of soil moisture. Furthermore, we focus on how the dynamics of soil moisture is represented in these frameworks. Previous studies on related topics (e.g. Kamgar et al., 1993; Famiglietti et al., 1999; Teuling et al., 2006; Brocca et al., 2007) were mostly based on non-continuous observations or short-term campaigns and focused on the investigation of absolute soil moisture values. By contrast, this study is based on 15-month-long continuous soil moisture measurements from 14 grassland sites of the SwissSMEX network over a larger scale $(150 \times 210 \mathrm{~km})$. It analyzes the decomposed absolute soil moisture, including its time-invariant temporal mean and its time-variant dynamics, expressed as anomalies. At the regional scale, the time-invariant term is influenced by factors that do not significantly change over time, such as topography, soil texture, land cover, and land use, while the time-variant dynamics are controlled by climate variables that change at synoptic, seasonal, and interannual time scales. Another aspect contributing to the time-invariant component is the climate regime over the considered time frame, which strictly speaking could be time varying if the analyzed time series spanned a longer time period, such as several years or decades. Reversely, some typically considered "static" components such as land use or soil texture may change over long time scales. The decomposition of the absolute soil moisture into its time-invariant and time-varying components enables us to investigate the spatio-temporal variability of absolute soil moisture with a focus on the contribution of these separate components. Using long-term measurements provides furthermore the possibility to analyze the temporal evolution of the spatial variability of soil moisture.

In the context of the SwissSMEX network, the environmental factors contributing to the time-invariant (static) and time-varying (dynamic) components of the analyzed data set are most likely soil texture and topography for the former, and meteorological and climate conditions for the latter (related to the commonly defined Swiss climatic regions; Müller, 1980). The effects of land cover and land use as further potential factors are not included, because the considered sites all have the same land cover (grassland). To investigate the possible role of some of the factors that could explain the identified patterns, Fig. 10 displays the average and standard deviation of $S_{t n}, M_{t n}$ and $A_{t n}$ when the sites are subdivided by climate region, soil texture, and elevation classes (see Fig. 1 for the definition of the climatic regions). The analysis shows that for these considered factors the averaged values for the different classes are generally within the standard deviation of the single classes, and thus none of the analyzed factors appear dominant in constraining the spatial variability of soil moisture. A partial exception are the mean values of $A_{t n}$ for the "climatic regions", which show that the mean $A_{t n}$ within single climatic regions is not always in the range of the standard deviation of other climatic regions. This suggests that the meteorological and climate forcing is not only important in explaining the common dynamic features within the network as highlighted earlier, but also in inducing spatial variations in these dynamics. Although the role of single factors is difficult to isolate from this analysis, one should note that the dynamic and static components may not only be influenced by the single factors considered here but also by a combination of these and other local factors (e.g. specificities of the sites and instrument locations, such as local slope, local variations in soil properties, the presence of stones, or the depth to the groundwater table, to mention a few).

First comparisons of the relation between the spatial variance and the spatial mean of the absolute soil moisture as well as the analysis of the temporal stability indicate an overall behavior that is consistent with previous reports from the literature (see Brocca et al., 2007, 2010, for a summary). Deviations of the relation between the spatial mean soil moisture and the spatial variance of soil moisture are mainly found for average dry moisture contents. The particularly dry 2011 spring displays almost constant absolute soil moisture during the recession of the spatial mean moisture content, while the variability of the anomalies indicates an increased variability during this period. 

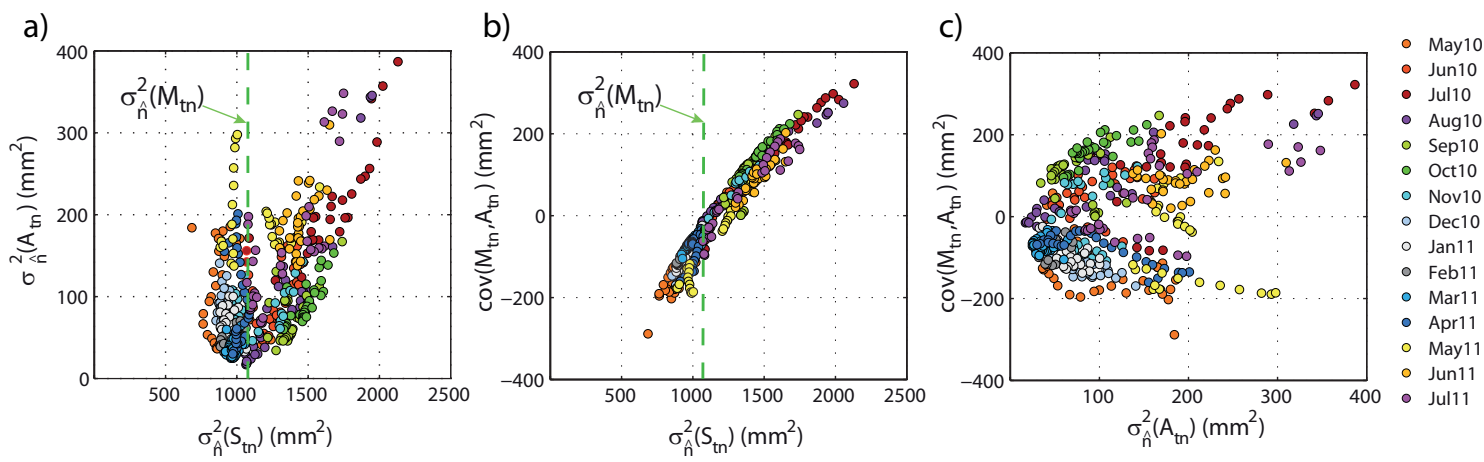

Fig. 6. Scatter plots of (a) the spatial variance of absolute soil moisture $\left(\sigma_{\widehat{\mathrm{n}}}^{2}\left(S_{t n}\right)\right)$ vs. spatial variance of anomalies $\left(\sigma_{\widehat{\mathrm{n}}}^{2}\left(A_{t n}\right)\right)$, (b) spatial variance of absolute soil moisture vs. spatial covariance of temporal mean and anomalies $2 * \operatorname{cov}\left(M_{t n}, A_{t n}\right)$, and of (c) spatial variance of anomalies vs. the spatial covariance between the mean and anomalies. The green dotted line represents the variance of spatial temporal mean $\left(\sigma_{\widehat{\mathrm{n}}}^{2}\left(M_{t n}\right)\right)$.
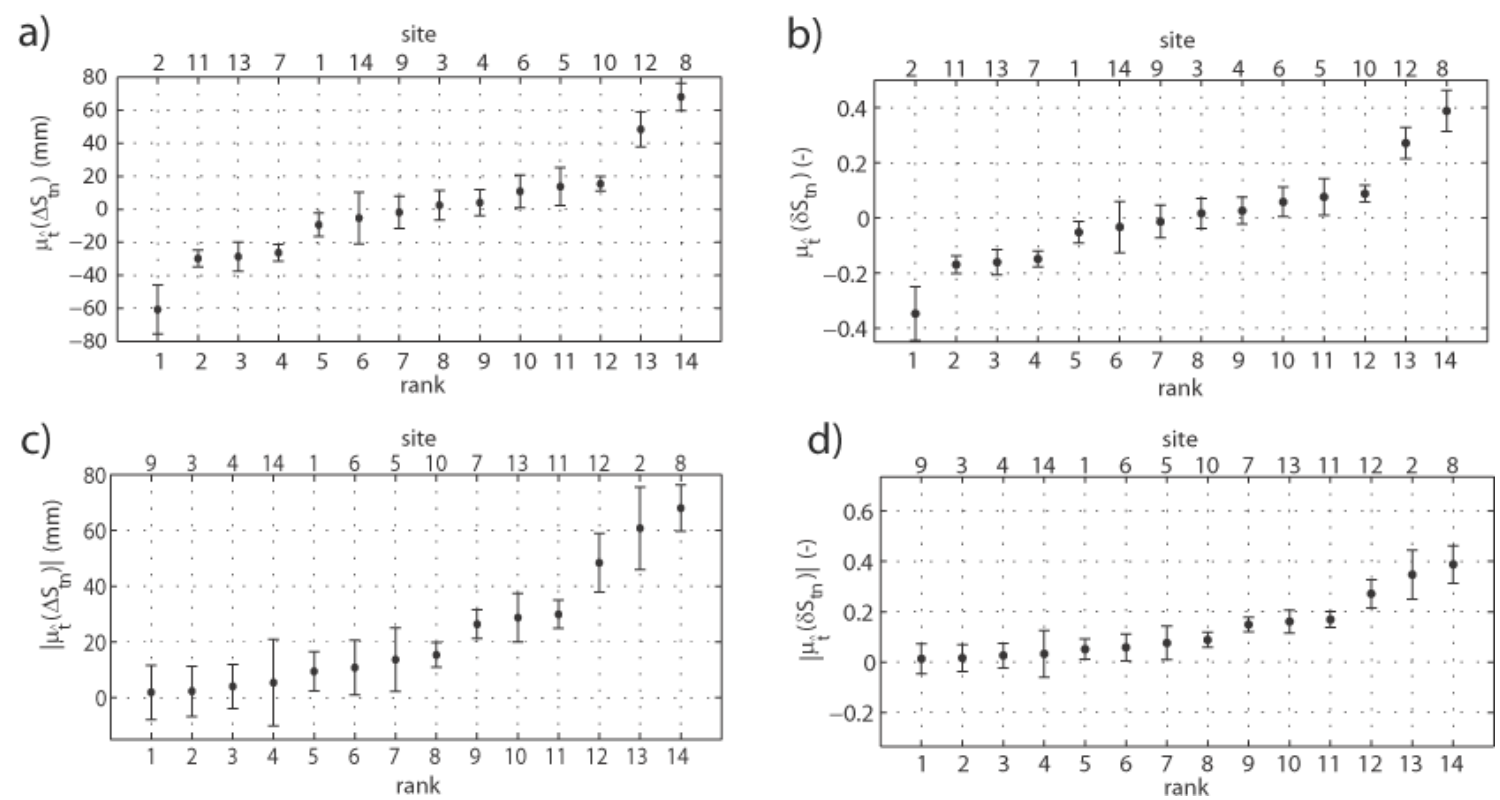

Fig. 7. Rank stability plots of (a) the temporal mean of relative difference of absolute soil moisture $\mu_{\widehat{t}}\left(\delta S\left(_{t n}\right)\right)$, (b) the temporal mean of difference of absolute soil moisture $\left(\mu_{\hat{\mathrm{t}}}\left(\Delta S_{t n}\right)\right)$, (c) the absolute values of temporal mean of the relative difference of absolute soil moisture $\left|\mu_{\hat{\mathfrak{t}}}(\delta S(t n))\right|$, and (d) the absolute values of temporal mean of difference of absolute soil moisture $\left|\mu_{\hat{\mathfrak{t}}}\left(\Delta S\left(_{t n}\right)\right)\right|$. The vertical lines represent \pm one standard deviation. The sites have been ranked according to their mean differences.

With respect to the temporal evolution of the spatial variability of absolute soil moisture and the contribution of its time-varying and time-invariant parts, the results reveal that the variance of the time-invariant mean is with 50 to $160 \%$ the largest contributor to the overall spatial variability. The variance of temporal anomalies contributes about 5 to $30 \%$. The covariance term of the temporal mean and anomalies results in correlations of both negative and positive signs, including periods of almost no correlation. For the DJF season, the relation is continuously negative with low variability over the whole period, whereas in the other seasons the correlation changes between positive and negative values, influenced by the meteorological conditions, with mainly positive values for JJA and SON. For periods with particularly wet but also particularly dry soil moisture conditions, as in the case of the dry 2011 spring, the correlation results in negative values and appears to get more negative with longer lasting duration. This implies that the rank of the sites with respect to their mean status is not the same for their anomalies. Indeed, for the studied period the particularly dry 2011 spring shows the strongest increase of a negative correlation between the spatial variance of absolute soil moisture and anomalies, resulting in different potential controls of spatial variability during such periods. Findings of the rank stability analyses 

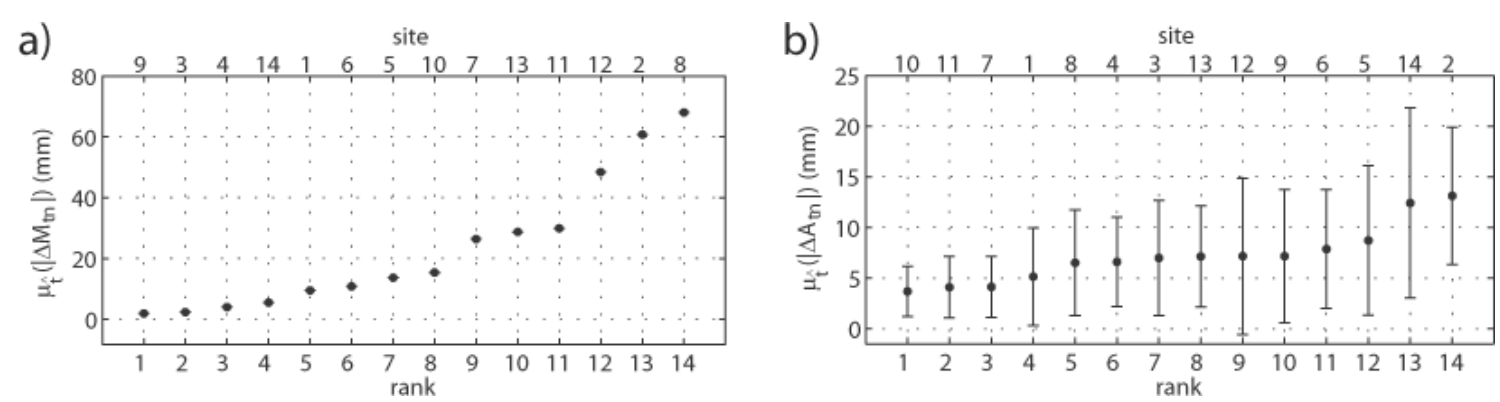

Fig. 8. Rank stability plots of (a) the absolute value of temporal mean $\left(\mu_{\hat{\mathfrak{t}}}\left(\left|\Delta M_{t n}\right|\right)\right)$, and (b) the temporal mean of the absolute values of differences of anomalies $\left(\mu_{\uparrow}\left(\left|\Delta A_{t n}\right|\right)\right)$. The vertical lines represent \pm one standard deviation. The sites have been ranked according to their mean differences.
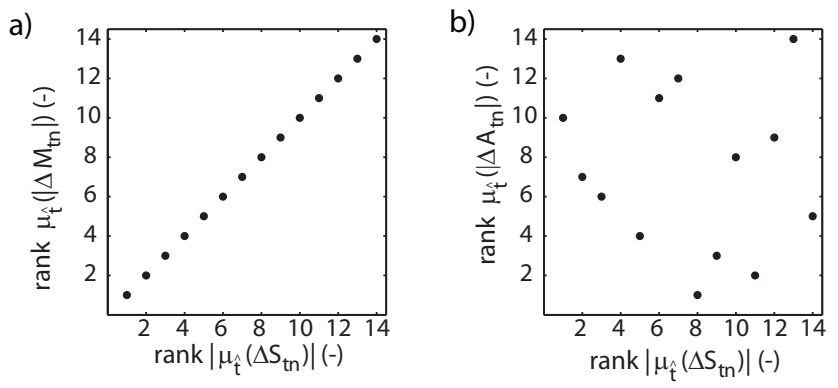

Fig. 9. Scatter plots of (a) the rank of absolute value of temporal mean $\left(\mu_{\hat{\mathrm{t}}}\left(\left|\Delta M_{t n}\right|\right)\right)$ vs. the rank of absolute values of temporal mean difference of absolute soil moisture $\left(\left|\mu_{\hat{\mathrm{t}}}\left(\Delta S_{t n}\right)\right|\right)$ and (b) the rank of absolute values of temporal mean difference of absolute soil moisture vs the rank of temporal mean of absolute values of differences of anomalies $\left(\mu_{\mathfrak{t}}\left(\left|\Delta A_{t n}\right|\right)\right)$.

confirm that the ordered ranks of the temporal mean absolute soil moisture are similar to the ranks of its mean state, while the ranks of the soil moisture dynamics are not consistent with this ranking. Indeed, sites that are identified as being most representative for the spatial mean do not correspond to the sites that are most representative for the average soil moisture dynamics within the network.

\section{Conclusions}

From this study, we conclude that frequently used frameworks assessing spatio-temporal characteristics of soil moisture networks need not generally apply to temporal soil moisture anomalies. Indeed, for the investigated data set, the analyses of the decomposed soil moisture reveal a small contribution of the dynamics to the overall variability of soil moisture. Reversely, this indicates a smaller spatial variability of the temporal dynamics than possibly inferred from the spatial variability of the mean soil moisture. Although the spatial variability of anomalies contributes with a smaller percentage to the whole spatial variance, its contribution is nonetheless not negligible compared to the actual values of

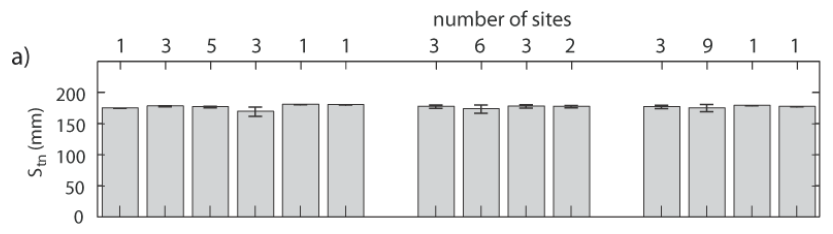

b)

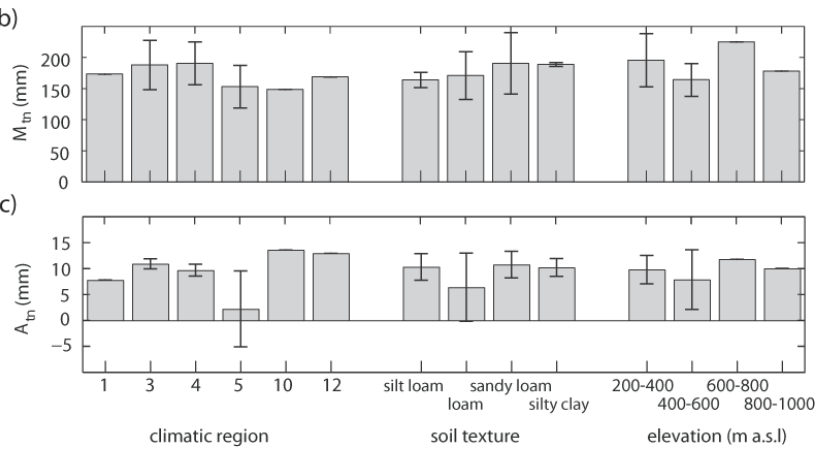

Fig. 10. Average and standard deviation over the respective sites for each climatic region (Müller 1980), soil texture and elevation of (a) absolute soil moisture $S_{t n}$ and its decomposed (b) time-invariant (temporal mean) $M_{t n}$ and (c) time-varying (anomalies) $A_{t n}$ component.

the temporal anomalies. Based on our results, we strongly encourage further analyses investigating the spatio-temporal characteristics of temporal soil moisture anomalies, in addition to assessments of those of absolute soil moisture alone. This is essential for investigations focusing on soil moisture dynamics, e.g. on runoff generation, drought development, and land-atmosphere interactions (e.g. Entekhabi et al., 1996; Seneviratne et al., 2010), weather and seasonal forecasting (e.g. Beljaars et al., 1996; Koster et al., 2010; Weisheimer et al., 2011) or climate change applications. To our knowledge, this is the first study focusing on the spatio-temporal variability of soil moisture that provides a separate analysis for its time-varying and time-invariant components. We encourage the application of the present framework to further long-term data sets. This would allow the assessment of the relative contributions of dynamic and static components to the spatial variability of soil moisture for different regions. 


\section{Notation.}

\begin{tabular}{|c|c|}
\hline$S_{t n}$ & soil moisture at site $n$ and time $t$ \\
\hline$M_{t n}$ & $\begin{array}{l}\text { temporal mean of soil moisture at site } n \text { and } \\
\text { time } t\end{array}$ \\
\hline$A_{t n}$ & $\begin{array}{l}\text { temporal anomaly of soil moisture at site } n \\
\text { and time } t\end{array}$ \\
\hline$P$ & precipitation \\
\hline$T_{\text {air }}$ & 2-m air temperature \\
\hline$\widehat{n}$ & subscript for spatial statistics \\
\hline$\widehat{\mathrm{t}}$ & subscript for temporal statistics \\
\hline$\mu_{\widehat{\mathrm{n}}}$ & spatial mean \\
\hline$\mu_{\widehat{t}}$ & temporal mean \\
\hline$\sigma_{\widehat{\mathrm{n}}}^{2}$ & spatial variance \\
\hline & temporal variance \\
\hline $\operatorname{cov}\left(M_{t n}, A_{t n}\right)$ & $\begin{array}{l}\text { spatial covariance between temporal mean } \\
\text { soil moisture of a site and its respective } \\
\text { anomaly }\end{array}$ \\
\hline$\Delta$ & absolute difference of spatial mean \\
\hline$\delta$ & relative difference of spatial mean \\
\hline
\end{tabular}

Acknowledgements. The SwissSMEX project is supported by the Swiss National Science Foundation SNSF (project 200021\#120289). We also gratefully acknowledge Irene Lehner and Karl Schroff for their support with the setup of the SwissSMEX network.

Edited by: L. Pfister

\section{References}

Albertson, J. D. and Montaldo, N.: Temporal dynamics of soil moisture variability: 1. Theoretical basis, Water Resour. Res., 39, 1274, doi:10.1029/2002wr001616, 2003.

Beljaars, A. C. M., Viterbo, P., Miller, M. J., and Betts, A. K.: The Anomalous Rainfall over the United States during July 1993: Sensitivity to Land Surface Parameterization and Soil Moisture Anomalies, Mon. Weather Rev., 124, 362-383, doi:10.1175/1520-0493(1996)124<0362:TAROTU>2.0.CO;2, 1996.

Bell, K. R., Blanchard, B. J., Schmugge, T. J., and Witczak, M. W.: Analysis of surface moisture variations within large-field sites, Water Resour. Res., 16, 796-810, doi:10.1029/WR016i004p00796, 1980.

Brocca, L., Morbidelli, R., Melone, F., and Moramarco, T.: Soil moisture spatial variability in experimental areas of central Italy, J. Hydrol., 333, 356-373, doi:10.1016/j.jhydrol.2006.09.004, 2007.

Brocca, L., Melone, F., Moramarco, T., and Morbidelli, R.: Soil moisture temporal stability over experimental areas in Central Italy, Geoderma, 148, 364-374, doi:10.1016/j.geoderma.2008.11.004, 2009.

Brocca, L., Melone, F., Moramarco, T., and Morbidelli, R.: Spatial-temporal variability of soil moisture and its estimation across scales, Water Resour. Res., 46, W02516, doi:10.1029/2009wr008016, 2010.
Cosh, M. H.: Variability of surface soil moisture at the watershed scale, Water Resour. Res., 40, 1-9, doi:10.1029/2004WR003487, 2004.

Entekhabi, D., Rodriguez-iturbe, I., and Castelli, F.: Mutual interaction of soil moisture state and atmospheric processes, J. Hydrol., 184, 3-17, 1996.

Entin, J. K., Robock, A., Vinnikov, K. Y., Hollinger, S. E., Liu, S. X., and Namkhai, A.: Temporal and spatial scales of observed soil moisture variations in the extratropics, J. Geophys. Res.Atmos., 105, 11865-11877, doi:10.1029/2000jd900051, 2000.

Famiglietti, J. S., Devereaux, J. A., Laymon, C. A., Tsegaye, T., Houser, P. R., Jackson, T. J., Graham, S. T., Rodell, M., and van Oevelen, P. J.: Ground-based investigation of soil moisture variability within remote sensing footprints during the Southern Great Plains 1997 (SGP97) Hydrology Experiment, Water Resour. Res., 35, 1839-1851, doi:10.1029/1999wr900047, 1999.

Famiglietti, J. S., Ryu, D., Berg, A. A., Rodell, M., and Jackson, T. J.: Field observations of soil moisture variability across scales, Water Resour. Res., 44, W01423, doi:10.1029/2006wr005804, 2008.

Guber, A. K., Gish, T. J., Pachepsky, Y. A., Van Genuchten, M. T., Daughtry, C. S. T., Nicholson, T. J., and Cady, R. E.: Temporal stability in soil water content patterns across agricultural fields, Catena, 73, 125-133, doi:10.1016/j.catena.2007.09.010, 2008.

Hupet, F., Bogaert, P., and Vanclooster, M.: Quantifying the localscale uncertainty of estimated actual evapotranspiration, Hydrol. Process., 18, 3415-3434, doi:10.1002/hyp.1504, 2004.

Jacobs, J.: SMEX02: Field scale variability, time stability and similarity of soil moisture, Remote Sens. Environ., 92, 436-446, doi:10.1016/j.rse.2004.02.017, 2004.

Kamgar, A., Hopmans, J. W., Wallender, W., and Wendroth, O.: Plotsize and sample number for neutron probe measurements in small field trials, Soil Sci., 156, 213-224, 1993.

Koster, R. D., Dirmeyer, P. A., Guo, Z. C., Bonan, G., Chan, E., Cox, P., Gordon, C. T., Kanae, S., Kowalczyk, E., Lawrence, D., Liu, P., Lu, C. H., Malyshev, S., McAvaney, B., Mitchell, K., Mocko, D., Oki, T., Oleson, K., Pitman, A., Sud, Y. C., Taylor, C. M., Verseghy, D., Vasic, R., Xue, Y. K., and Yamada, T.: Regions of strong coupling between soil moisture and precipitation, Science, 305, 1138-1140, 2004.

Koster, R. D., Mahanama, S. P. P., Livneh, B., Lettenmaier, D. P., and Reichle, R. H.: Skill in streamflow forecasts derived from large-scale estimates of soil moisture and snow, Nat. Geosci., 3, 613-616, doi:10.1038/ngeo944, 2010.

Martínez-Fernández, J. and Ceballos, A.: Temporal stability of soil moisture in a large-field experiment in Spain, Soil Sci. Soc. Am. J., 67, 1647-1656, 2003.

Mittelbach, H., Casini, F., Lehner, I., Teuling, A. J., and Seneviratne, S. I.: Soil moisture monitoring for climate research: Evaluation of a low-cost sensor in the framework of the Swiss Soil Moisture Experiment (SwissSMEX) campaign, J. Geophys. Res.-Atmos., 116, D05111, doi:10.1029/2010jd014907, 2011.

Müller, G.: Die Beobachtungsnetze der Schweizerischen Meteorologischen Anstalt. Konzept 1980, Arbeitsbericht der Schweizerischen Meteorologischen Anstalt, Zurich, 1980.

Robinson, D. A., Campbell, C. S., Hopmans, J. W., Hornbuckle, B. K., Jones, S. B., Knight, R., Ogden, F., Selker, J., and Wendroth, O.: Soil moisture measurement for ecological and hydrological watershed-scale observatories: A review, Vadose Zone J., 
7, 358-389, doi:10.2136/vzj2007.0143, 2008.

Robock, A., Schlosser, A., Vinnikov, K. Y., Speranskaya, N. A., and Entin, J. K.: Evaluation of AMIP soil moisture simulations, Global Planet. Change, 19, 181-208, 1998.

Seneviratne, S. I.: Terrestrial Water Storage: A Critical Variable for Mid-latitude Climate and Climate Change, Ph.D. Thesis, ETH Zurich, Zurich, Switzerland, 2003.

Seneviratne, S. I., Viterbo, P., Lüthi, D., and Schär, C.: Inferring Changes in Terrestrial Water Storage Using ERA-40 Reanalysis Data: The Mississippi River Basin, J. Climate, 17, 2039-2057, 2004.

Seneviratne, S. I., Luthi, D., Litschi, M., and Schar, C.: Landatmosphere coupling and climate change in Europe, Nature, 443, 205-209, doi:10.1038/nature05095, 2006.

Seneviratne, S. I., Corti, T., Davin, E. L., Hirschi, M., Jaeger, E. B., Lehner, I., Orlowsky, B., and Teuling, A. J.: Investigating soil moisture-climate interactions in a changing climate: A review, Earth-Sci. Rev., 99, 125-161, doi:10.1016/j.earscirev.2010.02.004, 2010.

Tallon, L. K. and Si, B.: Representative Soil Water Benchmarking for Environmental Monitoring, Journal of Environmental Informatics, 4, 31-39, doi:10.3808/jei.200400034, 2004.

Teuling, A. J. and Troch, P. A.: Improved understanding of soil moisture variability dynamics, Geophys. Res. Lett., 32, L05404, doi:10.1029/2004g1021935, 2005.

Teuling, A. J., Uijlenhoet, R., Hupet, F., van Loon, E. E., and Troch, P. A.: Estimating spatial mean root-zone soil moisture from point-scale observations, Hydrol. Earth Syst. Sci., 10, 755767, doi:10.5194/hess-10-755-2006, 2006.

Vachaud, G., Passerat De Silans, A., Balabanis, P., and Vauclin, M.: Temporal stability of spatially measured soil water probability density funcion, Soil Sci. Soc. Am. J., 49, 822-828, 1985.
Vereecken, H., Kamai, T., Harter, T., Kasteel, R., Hopmans, J., and Vanderborght, J.: Explaining soil moisture variability as a function of mean soil moisture: A stochastic unsaturated flow perspective, Geophys. Res. Lett., 34, L22402, doi:10.1029/2007g1031813, 2007.

Vinnikov, K. Y., Robock, A., Speranskaya, N. A., and Schlosser, A.: Scales of temporal and spatial variability of midlatitude soil moisture, J. Geophys. Res.-Atmos., 101, 7163-7174, 1996.

Weisheimer, A., Doblas-Reyes, F. J., Jung, T., and Palmer, T. N.: On the predictability of the extreme summer 2003 over Europe, Geophys. Res. Lett., 38, 1-5, doi:10.1029/2010GL046455, 2011.

Western, A. W., Grayson, R. B., Blöschl, G., Willgoose, G. R., and McMahon, T. A.: Observed spatial organization of soil moisture and its relation to terrain indices, Water Resour. Res., 35, 797810, doi:10.1029/1998wr900065, 1999.

Western, A. W., Grayson, R. B., and Blöschl, G.: Scaling of soil moisture : A Hydrologic Perspective, Annu. Rev. Earth Pl. Sci., 30, 149-180, doi:10.1146/annurev.earth.30.091201.140434, 2002.

Western, A. W., Zhou, S. L., Grayson, R. B., McMahon, T. A., Bloschl, G., and Wilson, D. J.: Spatial correlation of soil moisture in small catchments and its relationship to dominant spatial hydrological processes, J. Hydrol., 286, 113-134, doi:10.1016/j.jhydrol.2003.09.014, 2004.

Zhou, X., Lin, H., and Zhu, Q.: Temporal stability of soil moisture spatial variability at two scales and its implication for optimal field monitoring, Hydrol. Earth Syst. Sci. Discuss., 4, 11851214, doi:10.5194/hessd-4-1185-2007, 2007. 